\title{
Spirituality and social work: Introducing a spiritual dimension into social work education and practice
}

\section{Carol Phillips}

Carol Phillips has been a social worker since 1985, working in the community sector with prisoners and their families, with women affected by the criminal justice system, and as a fostering social worker, manager, supervisor and lecturer in social work at Te Wānanga o Aotearoa.

\section{Abstract}

Against a background of growing international interest in the place of spirituality in social work education and practice, this paper describes a qualitative study of the spiritual experiences of non-Māori social work students at Te Wānanga o Aotearoa, and the application of spirituality to their practice as social workers. The study found that both the programme and Wānanga environment enhanced and deepened participants' own spirituality and flowed through into their practice. Elements of the Wānanga programme which contributed to the students' spiritual development are identified, along with a discussion of the influence of the bicultural nature of the programme and take pū on their practice.

\section{Introduction}

This paper reports the findings of research into the experience of spirituality by six non-Maori students studying social work at two campuses of Te Wānanga o Aotearoa and how their spiritual experience translates into social work practice. The research, conducted as partial fulfilment for the degree of Master of Social Work, demonstrates that spirituality, as an integral part of the programme and a lived experience at the Wānanga, was a valued and important component of the programme for these students, contributing to both their own spiritual growth and understanding and their ability to work with spirituality in their social work practice.

\section{Definitions: Spirituality and religion, a Western perspective}

The literature generally distinguishes between spirituality and religion, religion being associated with organised belief systems and observances and spirituality with a broader sense of interconnectedness and self-fulfilment. However, some writers question the validity of this distinction, suggesting that it is unhelpful for social workers who have to work across a range of both spirituality and religion. Definitions of spirituality have therefore moved towards being more holistic and inclusive, influenced by multiculturalism and the need to work cross culturally. Canda and Furman's (2000) transemic approach, for example, encourages dialogue across cultures, while social justice and empowerment (Rice, 2002; Consedine, 2002) and environmental concerns (Consedine, 2002; Canda, 1998; Zapf, 2005; Derezotes, 2006a) have led to the development of an eco-bio-psychosocial-spiritual approach which expresses the idea of the interconnectedness of all living things with the universe. 
For the purposes of this study, Furman, Benson, Grimwood \& Canda's (2004, p. 772) definition of spirituality as, '...the search for meaning, purpose, and morally fulfilling relations with self, other people, the encompassing universe, and ultimate reality, however a person understands it' was adopted, along with their definition of religion as, '....an organised set of beliefs and practices shared by a community related to spirituality' (ibid).

\section{Indigenous influences on spiritual practice: An Aotearoa New Zealand perspective}

An emerging international body of work from Indigenous social work practitioners and academics insists that spiritual practice has always been part of holistic Indigenous social work. The importance of locating spirituality within culture, place and history is increasingly being recognised and there is evidence that Indigenous spirituality is beginning to influence Western ideas about social work practice (Baskin, 2002; Beatch \& Stewart, 2002; Pohatu, 2003; Ruwhiu, 2001). This is particularly so in Aotearoa New Zealand where research by Stirling (2008) suggests that social workers mainly associate spiritual practice with Māori spirituality.

Writing from a Māori perspective, Edwards (2009 p146) shares the view that religion has a narrower focus than spirituality, being concerned with rules and procedures, whereas according to his elders, ' ... spirituality comes from the ancestors, it lies within their karakia ... their karakia were not the prayers of the Pākehā'. While everything physical has a spiritual element, religion, he suggests, has a narrower focus and is about rules and procedures, '... the bureaucratic arm' (p. 250) of spirituality. This distinction, he says, is evident in hui where different religions share the service, but what is practised is Māori spirituality. For Benland (1988, p. 453) Taha Wairua, is, '... a reality much larger than any organised religion or cult', which manifested itself in pre-European Māori society as inseparable from the natural landscape, and in every person and relationship, and every living thing.

The all-encompassing and holistic nature of Māori spirituality is emphasised by Ruwhiu (2001, p. 63) for whom, '...the spiritual realm is always present, integrated into everything, the source of both pain and suffering and healing and wellbeing', and by Jenkins (1998, p. 493) who states that it, ' ...penetrates and permeates through the whole of life, supporting, nurturing and guiding the natural order'. It is concerned with mana, whenua, tapu and noa, tikanga and kawa and experienced as a 'lived phenomenon' (Ruwhiu, 2001, p. 65), imposing a set of social obligations for engagement with 'other dimensions of the universe' (ibid, p. 63).

\section{Spirituality in the social work context: A history of loss and re-discovery}

Despite having a long association with spirituality and religion through church-based welfare, Western social work, it has been argued, has become increasingly secularised through influences such as secular humanism, psychology, the development of evidence-based, scientific models of practice and growing reliance on government funding and a professionalised workforce (Russel, 1998; Lineham, 1994). Lineham (1994) suggests that even the church-based social services are now reliant on government funding and generally provide professional rather than faith-based services.

The 1990s, however, saw the beginning of a resurgence of interest in the spiritual aspects of social work, with academics and practitioners beginning to acknowledge spirituality as 
a missing piece of practice, so that there is now growing recognition of the importance of spirituality in holistic practice (for example Russel, 1998; Furman, et al., 2004; Canda, 1998; Sheridan \& Amato-von Hemert, 1999). Alongside this, research has suggested that while social workers are often willing to integrate spirituality in their practice, some feel unable to do so because they lack the tools or the confidence, or are afraid of being seen to unduly influence clients. (Furman, et al., 2004; Furman \& Benson, 2006; Holloway, 2007). Similarly, Western social work educators have struggled with including a spiritual component in social work education programmes due to concerns about proselytising, fear of offending students, or lack of confidence in their ability to teach it as a course component (Dudley \& Helfgott, 1990; Sheridan, Wilmer \& Aitcheson, 1994; Canda, 1998; Coholic, 2003; Praglin, 2004). Despite this, many social work students are expressing the desire for a spiritual component in their programme, and those who have undertaken programmes with spiritual content have expressed a high degree of satisfaction with the programme (Sheridan \& Amato-von-Hemert, 1999; Csiernik \& Adams, 2002; Ai, Moultine, Picciano, Nagada \& Thurman, 2004).

\section{Aotearoa New Zealand: Colonisation and dislocation}

In Aotearoa New Zealand the sophisticated social institutions and relationships which characterised Maori society prior to colonisation, and served to meet the needs of Māori communities, were undermined by loss of land, disease, and political, social and spiritual dislocation. The early settlers brought with them a very different model of 'welfare' based on the values of Victorian England, where poverty was regarded as a symptom of personal moral failure rather than resulting from lack of support or adverse social conditions, and charity was dispensed by the middle and upper classes to the deserving poor. As in Europe, churches were early providers of welfare in Aotearoa New Zealand, so that, '....welfare became part of the Christian outreach' (Tennant, 2007). Western ideas about welfare and wellbeing continued to drive the development of social work practice until Pūao-Te-Ata Tū, the Report of the Ministerial Advisory Committee on a Māori Perspective for the Department of Social Welfare (1986), pointed up the problems in the Department in regard to working with Māori. It was the 'culmination of a number of reports in which racism and cultural insensitivity figured large' (Nash, 1998, p. 332) and contributed to the growing impetus for a re-evaluation of social work education and practice in relation to Māori.

\section{The social work response}

Māori social workers and academics have documented how Western-based practice models have disadvantaged Māori recipients of social work services (Ruwhiu, 1999; Graham, 2002; Walsh-Tapiata, 2004; Matahaere-Atariki, Bertanees \& Hoffman, 2001) and challenged social workers to develop an understanding of the consequences of colonisation for Māori, using their collective knowledge and experience to develop and deliver appropriate practice models. To meet these challenges, Māori models of practice have been developed which are based on tikanga and utilise cultural concepts such as whanaungatanga, aroha, tautoko and ako. All these Indigenous models include taha wairua, the spiritual element, which was found to be lacking in many Western models. Perhaps the most well known of these models of practice are Mason Durie's (1982) Te Whare Tapa Wha and Rose Pere's (1997) Te Wheke, both of which use cultural symbols to present a holistic approach to working with whānau.

Māori academics have also critiqued social work education programmes, suggesting they may fail to create a climate in which Indigenous models can be nurtured. Foster (1999) believes this is because Māori values such as collectivity and spirituality are missing. Bishop, 
Berryman, Tiakiwi \& Richardson (2003) (in Raumati Hook, 2007) argue that the oppressive structures of society are replicated in the classroom when teachers fail to understand power imbalances and dominant cultural control is reflected in classroom relationships. Where this happens, Goldston \& Rauhiti-Fletcher (2003) believe that students are afraid of saying the wrong thing, and models and theories taught bear little relation to the reality of biculturalism. To counter this, Bishop et al (2003, p. 9) believe there needs to be 'a reassertion of Māori cultural aspirations, preferences and practices', while Stewart (2002) argues that cross-cultural connections need to be fostered in order build trust and share ideas in order to create a sense of belonging and cooperation.

\section{Spirituality in social work education in Aotearoa New Zealand}

While it would appear that most social work programmes in Aotearoa New Zealand address spirituality through mainstreaming, Nash (2002) describes how Massey University took a modular approach. A core module on spirituality was introduced as a way of recognising that spiritual belief is a motivating factor for some students entering the social work profession, and to ensure that Māori approaches to spirituality were also included. The module aims to 'help students to examine their own spirituality and that of others and to clarify the place of spirituality in social and community work practice' (p. 139). While it has raised issues such as the position of students in relation to what is taught, how the information is applied in practice, who has authority to teach and respect for sacred knowledge, it has attracted a diverse group of students, both Māori and non-Māori, and has been well received by students.

The social work programme at Te Wānanga o Aotearoa was developed specifically to encompass bi-cultural practice and incorporate and express a spirituality component. The Wānanga Capital Establishment Report (1999) states that the development of spiritual strength and depth among students is an integral part of the Wānanga programme, contributing to creating an environment which is conducive to learning physically, mentally, emotionally and spiritually. The social work programme at Te Wānanga o Aotearoa expresses this through incorporating take pū, applied principles, which direct activities, practices and relationships. Take pū embedded in the programme include:

Āhurutanga

Tino Rangatiratanga

Mauri Ora

Te Whakakoha Rangatiratanga

Kaitiakitanga

Tau Kumekume interpretation and people
Creating and maintaining quality space to ensure and promote the pursuit of best practice in any kaupapa

The constant recognition of absolute integrity of people in their kaupapa, relationships, positions and contributions in any context The constant acknowledgement that at the core of any kaupapa and relationship is the pursuit of wellbeing

Recognition that successful engagement and endeavour requires conscious application of respectful relationships with kaupapa

The constant acknowledgement that people are engaged in relationships with others, environments and kaupapa where they undertake stewardship obligations

The recognition that the ever-present tension in any kaupapa and relationship, positive or negative, offers insight and

(Te Tohu Paetahi Ngā Poutoko Whakarara Oranga, 2010 p5) 
These take pū act as, ' ...kaitiaki of valued principles, deep thinking, significant attitudes and ways of life, encapsulating the key essence of humanness, crucial to sustaining and assessing the quality of our kaupapa and relationships' (Pohatu: Takepū: Principled approaches to healthy relationships, undated, p. 2). Grounded in practice and re-used through time and space, they provide signposts to generations about how to live, behave and engage with others by '...invite(ing) Māori and others to constantly reflect on standards and quality, to consider takepū place and value in any context and time' (ibid).

The bicultural nature of the programme is designed to reflect the social services environment in Aotearoa New Zealand in the belief that, '...cultures within their distinctive communities can significantly benefit from understanding and respecting each other's unique positions and contributions' by 'consciously according equal space in every aspect of the learning system and methodology especially for Māori bodies of knowledge to actively participate alongside their western counterparts' (Te Tohu Paetahi Ngā Poutoko Whakarara Oranga, 2010, p. 20). All participants in the programme, both Māori and nonMāori, undertake the interpretation of both Māori and non-Māori bodies of knowledge and their application.

\section{The research}

The research was carried out when the writer was employed by Te Wānanga o Aotearoa as a kaiako teaching on the National Diploma in Social Work (NDSW) and was approved by both Te Wānanga o Aotearoa and Massey University ethics committees. It took the form of a qualitative study and entailed a series of in-depth interviews with six graduates of NDSW and Te Tohu Paetahi Ngā Poutoko Whakarara Oranga, Bachelor of Social Work (Biculturalism in Practice) (BSW) from two campuses of Te Wānanga o Aotearoa who were currently practising as social workers. The research explored the following areas:

- participants' views on spirituality and its importance in their own lives;

- their experiences of spirituality as social work students at Te Wānanga o Aotearoa;

- their views on spirituality and social work practice;

- the expression of spirituality in their social work practice;

- understanding and use of take pū in their social work practice.

This paper will focus on participants' experiences of spirituality at Te Wānanga o Aotearoa, their interpretation of take pū, and the integration of spirituality and take pū into their practice.

\section{Participants' views of spirituality}

The view of spirituality as expressed by Furman, et al. (2004, p. 772) was echoed by participants in the study whose own perceptions of spirituality were wide ranging, encompassing both religious beliefs and wider interpretations of spiritual experience. While two participants correlated spirituality closely with religion, all believed that spiritual experiences were broader than religious beliefs, though the two may intertwine. Participants spoke of spirituality as both personal, a source of fundamental values and core beliefs, closely associated with their inner being, sense of self and cultural heritage, country of origin and family name, and universal, related to an all-encompassing life force which is present in every living thing. 
Spiritual growth was associated with the life force within everything, with spiritual energy and with renewal and continuity in both nature and people. Out of this life force came human creativity. Spirituality could also be a source of inner peace and tranquillity. The absence of the spiritual element could be observed as a state of mauri moe, spiritual sleepfulness or stagnancy, often related to a sense of social failure and low self esteem. All participants related spirituality to a sense of connectedness, whether to nature, a life force, oneself, one's culture or to one another. This sense of connectedness became an integral part of the Wānanga experience and was a key factor in participants' perceptions of the spiritual aspects of the Wānanga:

I got to be part of others' spirituality and what it meant to them and was very blessed with being able to experience that spirituality from others and yet still be able to enhance my own.

(I made) connections, lots of connections, and hearing others' stories and where they've come from and how they got there.

\section{Experiences of spirituality at Te Wānanga o Aotearoa}

Most participants expressed some initial nervousness about entering a Wānanga environment, but this soon gave way to the feelings of acceptance and belonging which were part of the spiritual experience of being at the Wānanga. Building connections with fellow students through sharing stories and experiences, mutual support, learning together and sharing a common goal were all perceived as part of the spiritual dimension. This theme of acceptance and connectedness ran through the interviews, reiterated again and again by all the participants. For example at the pōwhiri:

All the staff were there and we came in; how do you explain what that feeling is that overwhelms you when everybody's singing and tears start; and all of a sudden you've got that sense of belonging? I would say that it was a spiritual connection. I felt on a spiritual level that I was exactly where I was meant to be. I was with the right people and I was in a place that I belonged.

Learning and living concepts such as whanaungatanga, aroha and awhi, learning pepeha and mihimihi, taking part in karakia, waiata, pōwhiri, noho marae and kapahaka were all described as spiritual experiences. Spirituality was experienced as something which arose naturally during the course of the day and was openly discussed, expressed and practised. Participants described how the integration of spirituality into teaching and everyday practice gave them permission to explore both the spirituality of the Wannanga and their own spirituality, and the confidence to integrate spirituality into their social work practice.

Particularly important for these non-Māori students was the opportunity to engage with another culture and its spirituality. The bicultural element of the programme, which legitimised both Māori and Western ways of knowing and understanding, contributed to participants' personal spiritual growth and understanding without overriding their own spirituality.

Te Tiriti o Waitangi and take pū provided a framework for cross-cultural engagement, along with teaching methods which encouraged engagement across culture, age, experience and status. 
The learning environment was described as safe, holistic, calm and whānau friendly and contributing to the overall spiritual experience. The study suggests that the teaching and learning methods employed were an important factor in creating this safe and holistic environment. Teaching methods based on ako, tuakana-teina, kanohi-ki-te-kanohi, hui and wānanga were all described as contributing to the sense of safety and belonging as well as facilitating learning. These methods also created an environment in which spirituality arose naturally and could be openly experienced and discussed. The shared spiritual and cultural knowledge and wisdom of older students was particularly valued. Experiential learning, through taking part in pōwhiri, noho marae, karakia, waiata and kapahaka was greatly valued as contributing to both cultural learning and experiencing spirituality as part of the daily life of the Wānanga:

I absolutely loved the Wānanga ... it was a really safe atmosphere ... I doubt that they (students at other institutions) get that sense of awhi, that sense of wairua, that sense of permission to be able to talk about this.

Each participant spoke of their own personal spiritual journey at the Wānanga. These ranged from regaining lost spirituality, to first discovery of spirituality, giving recognition to what was already present, and being given permission to explore and talk about spiritual matters. Participants experienced personal spiritual growth and deepened understandings of spirituality, and now felt more confident in acknowledging, and working with, spirituality in their practice. All participants reported that developing a sense of connection to Māori culture and beliefs connected with, and deepened, their own spiritually.

\section{Social work practice}

As discussed above, research suggests that while social workers are generally receptive to the idea of spiritual practice, many feel inadequately equipped to recognise and introduce a spiritual element into their personal practice. While participants were cautious about discussing religion with clients due to concern that such discussion had the potential to transgress ethical boundaries if they were perceived to be proselytising, they considered it ethically appropriate to discuss and incorporate spirituality into their practice.

Participants in this study saw their own spirituality as the basis for their spiritual practice, linking an understanding of their own spirituality to empathy, trust, being non-judgemental, acceptance of others' spiritual beliefs and practices, and being able to create a safe space for clients to explore spiritual matters. They reported that understanding, growing or refining their own spirituality at the Wānanga provided them with the base for their spiritual social work and gave them permission and confidence to use it. It also kept them safe when encountering and working with spiritualities other than their own:

I think you have to be able to know where you stand in relation to yourself to put yourself in relation to anyone else. I've worked with people who follow a darker path in spirituality. And I have supported people, because of my belief system, they've felt more comfortable talking to me. Working with those souls was quite powerful and quite challenging. It's not a threat to me and that is about being able to protect my own self and my own belief. And because I'm comfortable in it, I can walk into anyone else's world as a tourist and explore that, but not have to take it on. 
Spiritual practice began at assessment by exploring and uncovering strengths and potential spiritual links within the family/ whānau, such as kaumatua, kuia or other older people whose knowledge, wisdom or experience could offer support. Links to churches, cultural advisors or other spiritual sources were identified and activated. Spiritual strengths were identified through recognising and working with emotions such as joy, happiness, sadness, hope, hurt and loss. While the word 'spirituality' may not be used, conversations aimed at identifying, naming and exploring inner thoughts and feelings, values, beliefs, hopes and fears. Concepts such as happiness, peacefulness and fulfilment were all associated with spiritual practice, as were forgiveness and hope, both through being forgiven and forgiving others, so that spiritual healing could take place. Working with strengths and nurturing hope could both heal and be motivation for change. Participants talked about removing the mask, reactivating the mauri, restoring mana and drawing out the 'good' in people as elements of spiritual practice. By working with spiritual strengths, participants sought to encourage and support clients to make changes in their lives, awaken them to new possibilities, and restore the balance needed for holistic wellbeing:

Mauri moe is like stagnancy, be it depression, a stuck state of being in the same cycle of abuse, drugs, alcohol; being stuck spiritually, emotionally, physically. A lot of our dealings with families are when they are in a state of mauri moe and trying to help them shift to the next phase or state of being, mauri oho, which is like the start of a new day, or a new life, and having faith and hope, dreams and goals. And of course in the end, for all of us is mauri ora, the highest state of being that we want to achieve for ourselves and for our families.

While some participants used models of practice which overtly included a spiritual element such as Te Whare Tapa Whā and Mauri Ora, all were also able to introduce a spiritual element when using other models, particularly strengths-based practice and Maslow's Hierarchy of Needs, clearly demonstrating that spiritual practice is not dependent solely on models which overtly include a spiritual element. All participants aimed to deliver a holistic model of practice which included a spiritual dimension.

The spiritual element was also linked to culturally appropriate practice across a range of cultures. Experiencing Māori culture at the Wānanga sensitised participants to the centrality of culture to people's lives and gave them added awareness of the importance of cultural processes, protocols and rituals. One participant said that studying at the Wānanga, '... meant that I was exposed to different meanings of spirituality from (names individuals) and how they applied those in their personal and professional mode', while another said that it, '...just opened my eyes to myself and different cultures, and looking at similarities and differences and being able to acknowledge these in people'.

Participants said they would respect, and if appropriate participate in, protocols appropriate to the client, though for some participants working cross culturally with immigrant families raised ethical issues when cultural, religious or spiritual beliefs and practices conflicted with Western social norms and/or social work ethics. Their own spiritual awareness assisted them to work through these issues with the client.

All participants gave examples of how learning in a Wānanga environment had enhanced their practice with whānau Māori. They reported that having some understanding of concepts such as whānau, manaaki, awhi, being able to greet and introduce themselves in te reo, having some knowledge of karakia and waiata, experiencing pōwhiri, and staying on marae enhanced their ability to relate to, and be accepted by, Māori clients and whānau. 


\section{Take Pū}

The study also provided a snapshot of how a small number of non-Māori former students integrated take pū into their practice. Depth and breadth of understanding varied between participants, due in part to their level of exposure during the programme; those who had completed the BSW had considerably more exposure than NDSW students. Although most participants referred to take pū by their Māori names, they were generally applied in their Western meanings with only one significant reference to Māori meanings (the states of mauri). All but one of the participants (a graduate of an early programme where teaching of take pū was less developed and integrated into the programme) said that take pū were incorporated into their practice at some level. Take pū were variously described as a skeleton on which to hang practice, a practice base because they are a reminder of the fundamentals, a guide to practice ethics, and as being intertwined throughout practice. One participant had take pū on the wall in her office.

Âhurutanga (safe space) was interpreted as applying to the client, the worker, the agency, to any specific social work situation and to the worker's personal life. Many clients are not in a safe space, so that a social work task is to help them create a safe space. Āhurutanga was described as essential to establishing mana-enhancing relationships, while thinking about āhurutanga within a whanau can generate questions about safety and assist with working out strategies for moving into a safe space.

Whakakoha rangatiratanga (respectful relationships) were seen as the basis for practice and engagement with clients. Associated concepts were trust, being non-judgemental, and respect for clients' skills and knowledge. It was also important in relationships with colleagues and other professionals.

Taukumekume (positive and negative tensions) was seen as an important concept because how this was dealt with could affect both the social worker's relationships with clients and intervention outcomes. Safe space for dealing with negative emotions, and recognition that people move both forwards and backwards before making progress, were associated concepts.

Tino rangatiratanga (absolute integrity) was applied to ethical practice and relationships with clients, transparency, self knowledge, professional behaviour and personal integrity.

Mauri ora (wellbeing) was regarded as the goal of social work interventions and the basis of safe, client-oriented practice, when it takes account of client values and beliefs and focuses on what the client wants to achieve. The social work intervention must be holistic if it is to move clients towards mauri ora. One participant used the concept of the states of mauri - mauri moe, mauri oho and mauri ora - to describe the journey her clients took in their quest for wellbeing.

\section{Blocks to spiritual practice}

Although not included in the original methodology, this discussion arose spontaneously during interviews. In participants' experience, both agencies and individual social workers could create blocks to spiritual practice. Agency values and practices can make it difficult to 
include a spiritual element in practice, or agencies may be unwilling to recognise and deal appropriately with spiritual concerns, preferring to think of them as mental health issues or cognitive disorders. Colleagues may be unwilling to recognise the spiritual element of practice, or be so set in their own belief system that it acts as a block to recognising other forms of spiritual experience. Despite these blocks, all participants believed that the spiritual element should be an integral part of social work practice and found ways of incorporating it into their own practice.

\section{Conclusion}

As described above, the spiritual element of both social work education and social work practice was for some years neglected, but the last decade has seen a resurgence of interest in the spiritual aspects of practice, not least through growing recognition of the importance of spirituality to Indigenous peoples. However, both social work educators and practitioners have, for a variety of reasons, felt inadequate to the task of teaching or practising spirituality. In Aotearoa New Zealand, concern has been expressed about social work's ability to meet the needs of Māori clients, and the profession has been challenged to develop new practice models and teaching methods which take account of Māori cultural and spiritual needs.

For all participants in this study, recognising, reaching, reactivating and working with spirituality, was an important aspect of practice, but they believed that in order to work effectively in the spiritual realm, practitioners must both understand their own spirituality and be open to other understandings of spirituality. Being strong in their own spiritual beliefs assisted participants to be more open to talking about spirituality with clients with empathy and without judgement, and in being more open to and aware of, the spiritual aspects of practice. Spiritual practice was linked with overall wellbeing through holistic practice which considers every aspect of the person; mental, physical, emotional, spiritual and social. Participants acknowledged that the spirituality of the Wānanga environment had contributed to their ability to recognise, activate and work with the spirituality of their clients.

While participants wondered if Pākehā would be welcome in a Wānanga, what they experienced was a high level of connectedness, belonging and personal safety. The Wānanga environment and bicultural nature of the programme provided non-Māori students with an opportunity to engage with both their own and another culture's spirituality. Exploration and application of Te Tiriti o Waitangi, along with the bicultural application of take pū, provided a framework for engagement across cultures and spiritualities, modelled by Māori-Pākehā teaching partnerships. The result for students was described as a learning environment which was holistic and safe, encouraged open and supportive relationships, and by its very nature, provided students with encouragement and permission to engage with spirituality. Learning about and from Māori bodies of knowledge formed the basis of their personal spiritual development and learning and contributed substantially to their ability to engage with spirituality in their social work practice.

Specific elements of the programme delivery which contributed to its overall effectiveness were identified as:

- developing a sense of connectedness and belonging,

- being given permission to explore spirituality in a safe environment, 
- experiencing spirituality as integral to the programme so that discussion arose naturally,

- teaching methods such as ako, hui, wānanga, kanohi-ki-te-kanohi and tuakana-taina, which encourage reciprocal learning and learning partnerships,

- experiential learning through being included in spiritually-based rituals and practices.

Social work in Aotearoa New Zealand demands competency in working with Māori and increasingly with other cultures. The ability to recognise, activate and work sensitively with spirituality is a critical practice skill in this context. The students in this study benefited from an environment in which spirituality was openly acknowledged, valued and practised, both by the enhancement of their own spirituality and by being equipped with the tools and confidence to engage in spiritual practice. The bicultural nature of the programme and the opportunity to learn in, and from, a cultural environment different from their own, were acknowledged as crucial to both their personal spiritual development and spiritual practice. Despite encountering blocks to spiritual practice at both agency and individual levels, the Wānanga experience enabled them to not only work with practice models which include spirituality, but also adapt other models to include a spiritual element.

Acknowledgement. I would like to acknowledge my supervisors Dr Mary Nash and Dr Awhina English for their support and guidance when writing the thesis from which this article is taken.

\section{References}

Ai, A.L. Moultine, K., Picciano, J.F., Nagda, B.R., \& Thurman, L.H. (2004). Integrating spirituality into the social work curriculum: A student-initiated programme evaluation. Journal of Teaching in Social Work, 24(1/2).

Baskin, C. (2002). Circles of resistance: Spirituality in social work practice, education and transformative change. Currents: New Scholarship in Human Services, 1(1). University of Calgary Press.

Beatch, R., \& Stewart, B. (2002). Integrating Western and Aboriginal healing practices. In M. Nash \& B. Stewart (Eds). Spirituality and social care. Contributing to personal and community well-being (pp. 171-188). London \& New York: Jessica Kingsley.

Benland, C. (1988). The S-factor: Taha wairua. The dimension of the human spirit. In Royal Commission on Social Policy, Vol. 111, Part One (pp. 491-496). Wellington: Government Print.

Bishop, R., Berryman, M., Tiakiwi, S., \& Richardson, C. (2003). Te Kotahitanga: The Experience of Year 9 and 10 Māori students in mainstream classes. Report to the Ministry of Education.

Canda, E.R. (Ed). (1998). Spirituality in social work: New directions. New York: The Haworth Pastoral Press.

Canda, R.R., \& Furman, L.D. (2000). Spiritual diversity in social work practice. New York: The Free Press.

Coholic, D. (2003). Student and educator viewpoints on incorporating spirituality in social work pedagogy - An overview and discussion of research findings. Currents: New Scholarship in Human Services, 2(2). Calgary University Press.

Csiernik, R., \& Adams, D.W. (2002). The impact of social work education on students' spirituality. Currents: New Scholarship in the Human Services, 1(1). University of Calgary Press.

Dudley, J.R., \& Helfgott, C. (1990). Exploring a place for spirituality in the social work curriculum. Journal of Social Work Education, 26, 287-294.

Edwards, S. (2009). Titiro whakamuri kia marama ai te wao nei: Whakapapa epistemologies and Maniapoto Maori cultural identities. A thesis submitted in fulfilment of the requirements of the degree of Doctor of Philosophy, Massey University.

Foster, S. (1999). Addressing bi-culturalism in a teaching institution. Social Work Review, December 1999.

Furman, L.D., \& Benson, P.W. (2006). Practice and educational considerations: Cross-national perspectives from the United States, the United Kingdom, and Norway. Arete, 30(1), 2006, 53-62. University of South Carolina.

Furman, L. D., Benson, P.W., Grimwood, C., \& Canda, E. (2004). Religion and spirituality in social work education and direct practice at the millennium: A survey of UK social workers. British Journal of Social Work, 34, 767-792.

Goldston, J., \& Rauhiti-Fletcher, T. (2003). Kia mahi mo te whanau: Teaching in a bi-cultural classroom. Social Work Review, XV(1\&2). Autumn/Winter, 2003.

Graham, M. (2002). Creating spaces: Exploring the role of cultural knowledge as a source of empowerment in models of social welfare in black communities. British Journal of Social Work, 32, 35-49.

Holloway, M. (2007). Spiritual need and the core business of social work. British Journal of Social Work, 37, 265-280.

Jenkins, K. (1998). Te hono ki te wairua. The spiritual link: a Maori perspective on the spiritual dimension of social wellbeing. In Royal Commission on Social Policy, Vol. III, Part one (pp. 491-496). Wellington: Government Print. 
Lineham, P. (1994). A historical perspective on the New Zealand Christian Social Services in relation to church and state. A paper given to the New Zealand Council of Christian Social Services Consultation, 28-29 July 1994. Unpublished.

Matahaere-Atariki, D., Bertanees, C., \& Hoffman, L. (2001). Anti-oppressive practices in a colonial context. In Connolly, M. New Zealand social work, contexts and practice. Oxford University Press, Victoria, Australia.

Ministerial Advisory Committee on a Maori Perspective for the Department of Social Welfare (1986). Pūao-Te-AtaTü: Daybreak: The report of the Ministerial Advisory Committee on a Maori perspective for the Department of Social Welfare. Wellington, New Zealand: Department of Social Welfare.

Nash, E.G.M.A. (1998). People, policies and practice: Social work education in Aotearoa/New Zealand from 1949-1995. A thesis submitted in partial fulfilment for the degree of Doctor of Philosophy in Social Policy and Social Work at Massey University.

Nash, M. (2002) Spirituality and social work in a culturally appropriate curriculum. In M. Nash, \& B. Stewart (Eds). Spirituality and social care. Contributing to personal and community well-being (pp. 129-149). London \& New York: Jessica Kingsley.

Pohatu, T.W., \& Pohatu, H.R. (undated). Takepū: Principled approaches to healthy relationships. Te Wānanga o Aotearoa.

Pohatu, T.W. (2003). Maori worldviews: Source of innovative social work choices. Te Komako, Spring.

Pohatu, T.W., \& Pohatu, H.R. (undated). Takepū: principled approaches to healthy relationships. Te Wānanga o Aotearoa.

Praglin, L. (2004). Spirituality, religion and social work: An effort towards interdisciplinary conversation. Journal of Religion and Spirituality in Social Work: Social Thought, 23(4), 67-84.

Raumati Hook, G. (2007). A future for Maori education Part 11: The reintegration of culture and education. $M A I$ Review,1.

Russel, R. (1998). Spirituality and religion in graduate social work education. Social Thought, 18(2), 15-29.

Ruwhiu, L.A. (1999). Ko Tane Pupuke. Te Komako, Social Work Review, XI(4).

Ruwhiu, L.A. (2001). Bicultural issues in Aotearoa/New Zealand social work. In M. Connolly (Ed). New Zealand social work. Contexts and practice. Oxford University Press.

Sheridan, M.J., \& Amato-von Hemert, K. (1999). The role of religion and spirituality in social work education and practice: A survey of student views and experiences. Journal of Social Work Education, 35(1), 125-141.

Sheridan, M.J., Wilmer, C., \& Aitcheson, L. (1994). Inclusion of content on religion and spirituality in the social work curriculum. Journal of Social Work Education, 30, 363-376.

Stewart, B. (2002). Spirituality and culture. Challenges for competent practice in social care. In M. Nash, \& B. Stewart (Eds). Spirituality and social care. Contributing to personal and community well-being. London and New York: Jessica Kingsley.

Stewart, B., \& Wheeler, R. (2002). ‘Talk story' interview with Ross Wheeler. In M. Nash, \& B. Stewart (Eds). Spirituality and social care. Contributing to personal and community well-being. London and New York: Jessica Kingsley.

Stirling, B. (2008). Moving beyond acknowledgement: An investigation of the role of spirituality and religion within the professional practice of social work in Aotearoa/New Zealand. A thesis submitted for the degree of Doctor of Philosophy at the University of Otago, Dunedin, New Zealand.

Te Wananga o Aotearoa. Te Tohu Paetahi Nga Poutoko Whakarara Oranga, Bachelor of Social Work (Biculturalism in Practice) (2010).

Tennant, M. (2007). The fabric of welfare. Voluntary organisations, government and welfare in New Zealand, 1840-2005. Wellington: Bridget Williams Books.

Waitangi Tribunal Report. (1999). The wananga capital establishment report. Wellington: GP Publications.

Walsh-Tapiata, W. (2004). The past the present and the future: The New Zealand indigenous experience of social work. Social Work Review, XVI(4).

\section{Glossary}

Ako

Aroha

Awhi

Hui

Kanohi ki te kanohi

Karakia

Kaumātua

Kaupapa

Kawa

Mana

Marae

Mauri

Mihimihi reciprocal teaching and learning process

care, respect

support

meeting, to discuss

face to face

prayer, incantation

elder

matter for discussion, issue

protocol, custom

power or prestige-enhancing behaviour/relationships

courtyard in front of meeting house

life force

greeting 
Noa

Pepeha

Pōwhiri

Tapu

Tautoko

Te Reo

Tikanga

Tuakana-teina

Waiata

Wānanga

Wairua

Whānau

Whenua free from tapu

formal introduction

welcome ceremony

sacred, forbidden, confidential

support

Māori language

correct procedure, custom

mentoring support system

song

place of learning, to discuss deeply

spirit, spiritual aspect, soul

extended family

land 